\title{
Scientonomy 4
}

Oh, S. (2021). Scientonomy 4, 41-58

https://www.scientowiki.com/Oh_(2021)

https://doi.org/10.33137/js.v4i0.37122

\section{Element Decay}

\section{Sanghoon Oh}

Department of English, University of Toronto

sanghoon.oh@mail.utoronto.ca

\section{Keywords}

observational scientonomy, theoretical scientonomy, element decay, rejection without replacement, Poisson distribution, Aharonov-Bohm effect, Damascus steel, Greek fire, Cremonese violins

\begin{abstract}
This paper attempts to establish the existence of element decay by making a historical case for the existence of theory decay, a phenomenon where theories leave an agent's mosaic without any re-evaluation or decision on the agent's part. The phenomenon of theory decay is to be theoretically distinguished from rejection without replacement; while the latter is a result of an agent's deliberation, the former is a result of an agent's inaction. To locate historical instances of theory decay, there should be evidence that the agent under study existed continuously throughout the period under study, that the theory was accepted at some point and unaccepted at some later point, and that the theory left the mosaic without any decision on the part of the agent. With these indicators at hand, I discuss five potentially promising historical cases: Poisson distribution, the Aharonov-Bohm effect, Damascus steel, Greek fire, and Cremonese violins. I argue that there is solid historical evidence to interpret the last case as an instance of element decay, which is sufficient to establish the existence of the phenomenon. I show that element decay is best seen as a nonscientonomic phenomenon; its existence highlights that individual and communal agents have limited capacities of knowledge retention and transmission and, when these limits are reached, element decay often takes place. This suggests that sufficient epistemic capacity to retain and transmit knowledge is a necessary precondition for the existence of scientonomic patterns, which emerge and hold only when the agent has measures in place to counteract potential element decay.
\end{abstract}




\section{Introduction}

Element decay is a hypothetical phenomenon where elements of an agent's mosaic, such as questions, methods, and theories, cease to be part of the mosaic without any re-evaluation by the agent or any decision to reject that element. Essentially, it refers to scenarios where knowledge is lost as a result of such non-epistemic contingencies as censorship, political turmoil, violence, or deprivation of funding, among many others, rather than as a result of the agent's deliberation or decision. Importantly, the phenomenon of element decay is different from what can be called rejection without replacement. In the case of element decay, an element disappears from the agent's mosaic without any apparent criticism or decision to reject it. In the case of rejection without replacement, an element leaves the mosaic as a result of the agent's deliberation and decision to reject it. Thus, element decay is a result of the agent's inaction, while rejection without replacement is necessarily a result of the agent's decision. While in both cases we have an old element that leaves the mosaic without being replaced by any new element, the two phenomena are quite distinct. It is unclear at this stage whether any of these two phenomena actually exist. The goal of this essay is to explore whether there is such a thing as element decay through an exploration of theory decay, leaving the question of rejection without replacement to future studies.

There are some reasons to suspect that element decay might exist. One obvious indicator is the seemingly numerous cases from the history of science where a theory that was once accepted by a community is then rediscovered at some later time. For instance, certain pieces of technological knowledge like those required for

There might be a need to introduce a further distinction - that between the cases where knowledge is lost as a result of the epistemic agent's inability to act and the cases where knowledge loss takes place despite the epistemic agent's ability to prevent it. In the former scenario, the epistemic agent is affected by sociocultural factors (such as the threat of violence, destruction of archives, loss of funding, the death of masters, etc.) that prevent them from preserving their knowledge. In the latter scenario, the epistemic agent has all the necessary means at their disposal to prevent knowledge loss but nevertheless fail to do it. Only a more focused research into the typology of knowledge loss can tell us if we indeed need such a distinction.

the production of Damascus steel (a unique kind of forged steel known for its toughness) or Greek fire (flammable composition used in warfare by the Byzantine Empire) have been famously lost, leaving future generations baffled as to their precise composition. Similarly, ideas like Poisson distribution (a discrete probability distribution in the probability of outcomes) have been conceived and reconceived at various points in history, suggesting that they have also been forgotten at some stage. Thus, it seems as though there might have been some historical cases where a theory became accepted into an agent's mosaic despite the fact that it had already been accepted by the same epistemic agent at some prior point in time and, importantly, there is no record of that theory being rejected by the agent. There also seem to be many cases where accepted knowledge is not being transferred to the next generation due to some non-epistemic contingencies. Consider, for instance, a community of salmon fishermen that ran out of salmon to catch. In such circumstances, it would be highly unlikely for this community to continue passing on their knowledge of salmon fishing techniques to future generations. As a result, their accepted (albeit, likely tacit) knowledge of fishing techniques would be lost due to changes in their non-epistemic environment. What is yet to be established is whether such cases qualify as instances of element decay. 
If it turned out that there is in fact such a thing as element decay, it could have serious ramifications for our current scientonomic theory. According to the current formulation of the theory rejection theorem, a theory becomes rejected only when other theories that are incompatible with the theory become accepted (Barseghyan, 2015, p. 168). As element decay is clearly one of the scenarios forbidden by the theory rejection theorem, its existence would potentially imply that something is wrong with the theorem. Now, in the current scientonomic theory, the theory rejection theorem is a deductive consequence of the compatibility corollary that states "at any moment of time, the elements of the scientific mosaic are compatible with each other" (Sarwar \& Fraser, 2018, p. 71) and the first law for theories that states "an accepted theory remains accepted unless replaced by other

In his discussion of the potential violations of the laws of scientific change, Barseghyan mentions a number of examples of hypothetical violations of the first law (Barseghyan, 2015, p. 238). In one of these scenarios, the only copy of the manuscript where the communal knowledge has been collected is being destroyed, resulting in the loss of at least some parts of the communal mosaic. This hypothetical scenario seemingly violates the first law as some of the accepted theories "cease to be accepted without being replaced by any other theory" (Barseghyan, 2015, p. 238). What remains to be seen is whether there are any actual examples of such decay and, if so, whether they in fact violate the first law. theories" (Barseghyan, 2015, p. 168). While the corollary itself follows from the definition of compatibility, the first law for theories follows from the first law, according to which "an element of the mosaic remains in the mosaic unless replaced by other elements" (Barseghyan, 2015, p. 124). Therefore, if it turned out that there is such a thing as element decay, not only could the theory rejection theorem potentially become compromised, but also the first law itself (since the other premise of the theorem's deduction - the corollary - is an analytic proposition, a

rejection of the theory rejection theorem would also require a rejection of the first law). If element decay were to exist, it could potentially entail that the first law in its current formulation doesn't hold, for the first law implies that accepted elements stay accepted by the agent unless replaced by other elements; it could potentially have serious consequences for our current scientonomic knowledge.

But before we consider the scientonomic implications of element decay, we must first explore whether there is such a thing as element decay. While it is conceivable that there might also exist a decay of questions and methods, in this paper, I will focus primarily on theory decay, i.e. I will focus on locating historical cases where agents "forget" theories that were once accepted in their mosaics. I will begin by outlining some possible indicators that can help us locate historical cases of element decay and consider a number of potentially useful search strategies. I will then consider five historical cases of lost knowledge with the goal of locating actual instances of element decay: the rediscoveries of Poison distribution and the Aharonov-Bohm effect, as well as the lost knowledge of Damascus steel, Greek fire, and Cremonese violin. The paper will culminate with a discussion of some potential implications of our findings.

\section{Indicators of Theory Decay and Possible Search Strategies}

As the very existence of theory decay is, at this stage, a matter of conjecture, the first question that should be addressed is what sort of indicators could, in principle, show that the phenomenon exists. One possible complication here is that the phenomenon itself might be detectable only indirectly. After all, if an element has been forgotten, how can there be any records of this decay? If there were records of the agent's decision to reject the element, that would no longer be an instance of theory decay, but that of usual theory rejection. While it may be impossible to observe theory decay directly, the phenomenon - if it exists - should be detectable through a combination of indicators. To have a legitimate claim that the phenomenon of theory decay exists, we have to ensure that all of the following conditions are met:

- Agent Continuity: there should be historical evidence that the agent in question continuously existed during the time period under study.

- Change from Theory Acceptance to Unacceptance: there should be clear indications of a theory being accepted at some point and unaccepted at some later point.

- $\quad$ Theory Unacceptance Without Assessment: there should be clear evidence that the theory became unaccepted without any theoretical assessment on the part of the agent. 
These three indicators are singled out for their empirical utility. While in principle there might be other indicators of theory decay, these three are sufficient to successfully identify instances of theory decay. Let us consider these conditions in turn.

First, we should ascertain that we are dealing with one epistemic agent that existed continuously during the Naturally, the phenomena of question decay and method decay - if they exist - would probably have their own indicators that might not fully overlap with those of theory decay. Only future research will show whether there is such a thing as question or method decay and, if so, what their respective indicators are. whole duration of the transition. As this requirement applies primarily to communal epistemic agents, we must make sure that the community in question existed both prior to and after the purported decay. If it turns out that the theory was "lost" because the community itself ceased to exist, that won't qualify as an instance of theory decay, since we won't have any post-decay mosaic to speak of. Similarly, if it turns out that the alleged decay concerned not one but two different communities - with the theory in question being part of one earlier community's mosaic but not part of the mosaic of some later community - then we won't have an instance of theory decay. Thus, it is important to establish whether the community in question existed continuously for the duration of the transition, especially when the precise time of the transition is unknown, and we can only narrow it down to a certain time period that spans across several generations. We seem to have some indicators of such a continuous existence of the community. These include uninterrupted publications of the community's academic journals, courses continuously taught by the members of the community at educational institutions, uninterrupted series of conferences, meetings, and workshops organized by the community, as well as the continuous existence of its respective social institutions (universities, guilds, associations, etc.). These can be established through the study of academic publications, university curricula, minutes of meetings, family trees (if certain theories are passed down by inheritance), etc. One way or another, to claim that we have found an instance of theory decay, we have to ensure that we are dealing with one epistemic agent that can be shown to have existed continuously over the period bracketing the transition.

Second, we must find clear indicators showing that the theory in question was accepted by the agent at some point in time and then unaccepted by the agent at some later point. For this, the usual scientonomic indicators can be used - publications in academic journals and encyclopedias, inclusion in textbooks and university curricula, as well as any other indicators relevant to the specific agent (Barseghyan, 2015, pp. 114-118; Fatigati 2017). One possible challenge here is to ensure that the theory in question indeed became unaccepted, rather than neglected. The fact that the theory stopped being mentioned in academic journals, encyclopedias, or textbooks may simply indicate that it was no longer pursued by the agent (i.e. that it was neglected), rather than unaccepted. Thus, compared to establishing that the theory was at some point accepted, establishing that it became unaccepted at some later point is a much more challenging task, as instances of neglect and unacceptance often have similar historical markers. Despite these complications, I believe there might be some indicators that would help us delineate cases of neglect from those of unacceptance. One such marker is the fact of the re-acceptance of a theory, i.e. when the theory that was previously accepted and then allegedly unaccepted becomes accepted. Luckily, there is at least one solid indicator of re-acceptance: if we can show that the theory was actively evaluated (debated, scrutinized, tested, etc.) by the agent and then accepted into the agent's mosaic, then we can legitimately claim that we are dealing with two distinct periods of acceptance with the unacceptance interval in between.

Finally, we must ensure that the theory's transition from accepted to unaccepted is not accompanied by any debates or discussions concerning the theory. If we find out that just prior to the alleged decay there was a communal discussion of the merits of the theory, that will be a good indicator that we are dealing not with an instance of theory decay but with that of regular theory assessment and rejection. Thus, the challenge here is to ensure that the period preceding the alleged instance of decay is thoroughly studied and no traces of individual or communal deliberation concerning the theory are found. Journal and encyclopedia articles, textbooks, conference proceedings and other indicators relevant to the agent and time period in question should be methodically scrutinized. This is of course very difficult to do in practice, since it is always possible that the lack of historical evidence for the existence of prior debates is due to the inherent incompleteness of our historical record. Suppose, for instance, we find that the theory was absent from textbooks and encyclopedias despite its presence in previous 
editions. Even if we find no evidence of the assessment of the theory prior to the alleged decay, we should nevertheless proceed cautiously and only tentatively suggest that we have located an instance of theory decay.

Now, how should one go about searching for instances of theory decay? While it would be unwise to a priori exclude any search strategies, at this stage, it seems advisable to focus on more promising directions first. I shall argue that it seems reasonable to start our search for possible instances of theory decay from cases where knowledge is transmitted orally, rediscovered, or occupies a rather fringe position in the agent's mosaic. In all of these cases, there seem to be prima facie reasons to expect that the hypothetical phenomenon of theory decay is likely to be observed. Let us consider these three search scenarios in turn.

One potentially fruitful direction is communities that involve oral transmission of knowledge. Even in those cases when knowledge can in principle be transmitted through written transcriptions (e.g. cookbooks, guidelines, manuals, etc.), such a transmission may not always align with the interests of the agent. For instance, certain aspects of technical knowledge like trade secrets are often fiercely guarded, as they give the agent an 'edge' over their competitors. These trade secrets are often transmitted orally, since their transcription would allow for the possibility of theft or dissemination, resulting in the loss of the competitive advantage. Generally speaking, technical knowledge is often passed down from master to apprentice or within members of a guild orally, rather than through written text. Studies of oral transmission of knowledge in various communities suggest that in such cases some knowledge loss is common (Aunger, 2000; Gómez-Baggethun et al, 2010; Reyes-García et al, 2009). Thus, it seems plausible that knowledge preserved and transmitted in an oral form is more likely to be subject to element decay than written knowledge.

Theory rediscovery is another potentially fruitful direction for locating instances of theory decay. As mentioned earlier, there have been several historical cases, such as that of Poisson distribution, where a once accepted theory was rediscovered at some later point (Johnson, Kemp, \& Kotz, 1992, pp. 151-152). In such cases, the two periods of acceptance are separated by a period of unacceptance. But if a theory becomes accepted by the same agent for the second time, this means that the theory was either rejected after the first acceptance or it was simply forgotten (i.e. decayed). So, if there is no discernible indication of the theory being deliberately rejected by the agent after the first acceptance, then the only remaining conclusion is that the theory decayed before it was rediscovered and accepted for the second time. If we were able to show that the same theory was accepted by the same epistemic agent more than once in the absence of any records of that theory being deliberately rejected between these acceptances, then we might have a legitimate claim that we found an instance of theory decay.

Yet another potentially fruitful search strategy involves focusing on what can be called fringe theories. It seems reasonable to suggest that theories of a typical mosaic will range from more central to more peripheral. Thus, for Newtonian physicists, the three laws of motion and the law of gravity would play a much more central role than some specific experimental data. Similarly, for evolutionary biologists, the key theories concerning the mechanisms of genetic variation, inheritance, and natural selection would be much more central than claims on the number of dinosaur species or data sets from specific biological case studies. Whether there are any objective

A number of prominent philosophers of science have attempted to conceptualize this phenomenon. For instance, the constitutive principles of Kuhnian paradigms are thought of as much more central than answers to specific puzzles that scientists aim to solve during normal science (Kuhn, 1996). Similarly, Lakatosian hard cores are more central to the research program than specific auxiliary hypotheses (Lakatos, 1970), while Laudan's research traditions are characterized, among other things, by "a number of specific theories which exemplify and partially constitute" them (Laudan, 1977, p. 78). Scientonomy currently lacks any such distinction due to the fact that the laws and theorems currently describing the mechanism of theory acceptance and rejection apply to all theories regardless of their real or perceived centrality. It remains to be seen whether scientonomy in fact needs to introduce such a distinction. grounds for such a spectrum is irrelevant here; what's important is that many epistemic agents seem to view the theories in their mosaic in such a spectrum. Now, it is reasonable to suspect that when such agents transmit their knowledge from one generation to the next, they place greater emphasis on preserving perceived core theories over perceived fringe theories. It is conceivable, therefore, that some fringe theories will not be transmitted to the next generation and will be forgotten. Thus, if there is such a thing as theory decay, it is more likely to be more widespread among fringe theories rather than more central theories. 
With these search strategies at hand, we can now proceed to considering several historical cases with the goal of locating instances of theory decay. I will look into the following five episodes: the rediscovery of Poisson distribution, the Aharonov-Bohm effect, as well as the notable cases of loss of knowledge concerning the production of Damascus steel, Greek fire, and Cremonese violins. The following sections of this paper summarize our findings.

\section{Case 1: Poisson Distribution}

In March 1711, Abraham de Moivre published an article titled De Mensura Sortis where he presented a probability distribution that accounts for the frequency of an event within an interval of time. Among other things, this distribution is useful for predicting independent events and estimating changes in population in the future; it was famously used by economist Ladislaus Bortkiewicz to predict the number of Prussian cavalry soldiers killed by horse-kicks (Hald, de Moivre, \& McClintock, 1984, pp. 234-235; Preece, Ross, \& Kirby, 1988, p. 1). However, we now recognize this probability distribution as a Poisson distribution after Simeon Demise Poisson's publication of his book Researches into the Probabilities of Judgment in Criminal and Civil Cases in 1837 (Johnson, Kemp, \& Kotz, 1992, p. 151; Poisson, 2013). Given that Poisson and de Moivre had both formulated identical probability distribution sets, there is a good chance that we might be dealing with an instance of theory decay.

At the time of their respective publications, both de Moivre and Poisson were prominent members of their mathematical communities. During his lifetime, de Moivre was a leading mathematician in Britain as a member of the British Royal Society (Heyde \& Seneta, 2001, pp. 45-46; The Royal Society, 2007; Bellhouse \& Genest, 2007, pp. 115-116). Following the publication of his 1711 article, he further developed his statistical theories and presented them - including his distribution set - in his book, The Doctrine of Chances. First published in 1718, the book became a widely used textbook on probability until replaced by Laplace's Théorie Analytique des Probabilités in 1812 (Hald, De Moivre, \& McClintock, 1984, p. 230; Bellhouse, 2011, pp. 32, 133, 135-136). As for Poisson, he became a professor of mechanics in the faculté des sciences de Paris in 1809. After becoming an Académie member, Poisson authored numerous statistical works, leading to the publication of his influential 1837 book (Heyde \& Seneta, 2001, pp. 123-126). These indicators provide some grounds to suggest that both de Moivre's and Poisson's distributions were accepted by their respective communities.

The problem, however, is that de Moivre mainly worked in the United Kingdom under the British Royal Society, whereas Poisson published many of his work under the Académie des Sciences in Paris. Thus, we are dealing not with one but with two communal epistemic agents here. There were, of course, many instances of cooperation between these two communities, like in the field of geodesy (Crosland, 2005, pp. 30-31). Even in the field of mathematics, the two mosaics certainly influenced each other. For example, some of the theories that Poisson worked with, like the de Moivre-Laplace limit theorem for which he provided his own derivation, indicate that at least some of de Moivre's theories were accepted in the French mosaic (Sheynin, 2017, p. 126). In addition, Poisson's induction as a fellow of the British Royal Society in 1818 (The Royal Society, 2007) indicates that at least some of his theories were known and accepted by the British community. Yet, given that these were two different communities operating in two rival nations, it is unclear to what extent knowledge was shared between the two communities; communication between the two communities was cut between 1756-1763, 1777-1783, and 1793-1815, as their respective nations were at war with one another (Crosland, 2005, pp. 26, 30-31). Specifically, it is unclear whether the French community was even aware of de Moivre's distribution and, if so, whether it was accepted in the French mosaic. It is equally unclear whether de Moivre's distribution was ever forgotten by the British community prior to their acceptance of Poisson's distribution.

In my search for historical indicators, I have not found sufficient evidence showing that the Académie had been aware of de Moivre's distribution when they had awarded de Moivre his membership. The Académie clearly recognized de Moivre's statistical work when providing him with membership status in 1754 (Heyde \& Seneta, 2001, p. 46; Bellhouse \& Genest, 2007, p. 129). However, the corpus of de Moivre's works extends far beyond 
this single probability distribution and includes considerable research on many other topics, such as gambling (Hald, de Moivre, \& McClintock, 1984, p. 230). Thus, at this stage, we lack evidence to confirm that the Académie was even aware of de Moivre's distribution.

As for the British community, while they accepted de Moivre's distribution, I have not been able to find any historical indicators of its decay from the British mosaic. Thus, I cannot say whether they reaccepted the distribution when it was rediscovered by Poisson, or whether the distribution was accepted for the whole duration of the episode. Specifically, it would be helpful to know how Poisson's distribution was received by the British community: did they consider it as an important new discovery or a reiteration of what they already knew from de Moivre? At this stage, we lack indicators to determine the British community's stance on Poisson's formulation.

In short, since the British Royal Society and the Académie des Sciences were institutions of two distinct communities with their own independent mosaics and since we lack evidence to establish that de Moivre's distribution was accepted in the French mosaic, we cannot confirm that the theory actually decayed prior to its rediscovery by Poisson. Ultimately, there is insufficient historical evidence that the French or British communities had forgotten de Moivre's distribution prior to the acceptance of Poisson's distribution. If one were to find any indicators that de Moivre's distribution was accepted by the Académie when they awarded de Moivre his membership in 1754 but was forgotten by the time of publication of Poisson's 1837 book, one would have a strong case for the existence of theory decay. However, until such evidence is found, we should interpret this as a case of the same theory being accepted by two different agents in two different mosaics.

\section{Case 2: Aharonov-Bohm Effect}

A similar case can be seen with the Aharonov-Bohm effect. In 1958, Yakir Aharonov and David Bohm discovered that despite a negligible level of a magnetic field, an electron experiences a phase shift when traveling within a closed loop. The importance of their discovery was a confirmation of a novel prediction within quantum mechanics regarding the existence of quantum fields (Lyre, 2009; Peshkin \& Tonomura, 1989, pp. 7-9). However, in 1949, Werner Ehrenberg and Ray Siday at Edinburgh University published the same findings in their paper The Refractive Index in Electron Optics and the Principles of Dynamics. Thus, Ehrenberg and Siday had discovered the same phenomenon nine years prior to Aharonov and Bohm's discovery (Berry, 2010; Hiley, 2013, pp. 1-2, 10). Aharonov and Bohm were informed about Ehrenberg and Siday's findings only after the publication of their paper. In a follow up paper, Aharonov and Bohm acknowledge that they had come to the same result as Ehrenberg and Siday (Hiley, 2013, pp. 10-11; Sturrock \& Groves, 2010). Given that we are dealing with essentially the same theory here, it appears as though the scientific community had accepted this theory twice, which might be indicative of theory decay.

Yet this case fails to exhibit all the necessary conditions of theory decay for a couple of reasons. First, while both Ehrenberg \& Siday and Aharonov \& Bohm discovered the same phenomenon as members of the physics community, it is highly debatable whether Ehrenberg and Siday's discovery was widely known, let alone accepted, by the global physics community. Those few individuals who were aware of the Ehrenberg and Siday's discovery understood its importance in the context of quantum mechanics and accepted it. For instance, there is an anecdotal account that Leonard Schiff, the quantum mechanics expert at Stanford, found Ehrenberg and Siday's findings convincing in 1955, three years prior to Aharonov and Bohm's publication (Sturrock \& Groves, 2010). Yet, it is unlikely that Ehrenberg and Siday's findings were known to the physics community in general or quantum physics subcommunity in particular. One reason for this is that Ehrenberg and Siday presented their proposal in the context of electron optics, using jargon that made their work less accessible to other physics subcommunities. In addition, the importance of their discovery was de-emphasized by its restricted presence in the discussion section of the paper (Berry, 2010). Furthermore, the journal where Ehrenberg and Siday's article was published, Proceedings of the Physical Society, had problems proliferating their discovery. Because this was prior to the British Institute of Physics taking over the British Physical Society, the journal did not have much 
international recognition. Although it was one of the main British journals at the time, it was not a leading journal in the global physics community. In short, we have no evidence indicating that Ehrenberg and Siday's findings were accepted by the physics community in general or by the quantum physics community in particular (Hiley, 2013, pp. 10-11).

In contrast, Aharonov and Bohm presented the phenomenon as the primary focus of their paper, explicitly discussing its implications for quantum mechanics. Their paper, published in the American Physical Society in 1959 , sent immediate shockwaves through the physics community, as it was an observation that confirmed a novel prediction of quantum theory (Hiley, 2013, pp. 10-13; Peshki \& Tonomura, 1989, pp. 7-10). Thus, there is solid historical evidence that the quantum physics community and, subsequently, the larger physics community were aware of and accepted Aharonov and Bohm's findings; yet, importantly, neither quantum physicists nor the global physics community were aware of Ehrenberg and Siday's discovery.

In summary, although there is some evidence showing that the effect discovered by Ehrenberg and Siday in 1949 was accepted by some individual scientists, due to its mode of presentation and publication, it likely remained unknown to the larger physics community until after the publication of Aharonov and Bohm's paper. Therefore, in this case we cannot speak of any theory decay, as we don't have any evidence showing that the theory in question was accepted by the relevant epistemic agent in the first place.

\section{Case 3: Damascus Steel}

Our next potential candidate for theory decay is technological theories involved in the production of Damascus steel. Damascus steel was likely first produced circa $500 \mathrm{CE}$ from ingots sourced from India that were forged in Damascus, Syria, and was renowned for its great strength and hardness, as well as its characteristic surface patterns (Verhoeven, Pendray, \& Dauksch, 1998; Sherby \& Wadsworth, 2001, pp. 348-349). The proliferation of these blades from the sixteenth to eighteenth centuries make it seem easy to reverse-engineer their production process. Yet, the details of the process are still lost to us, despite numerous attempts to revive this knowledge. But regardless of whether we are nowadays successful in recreating the precise steps of the production process, what is important is the historical fact that this knowledge was lost at some stage, for "after around 1850 no one could make one" (Verhoeven et al., 2018p. 1331). This gives us some reason to suspect that we may be dealing with an instance of theory decay.

To find out if this is in fact an instance of theory decay, we should study how exactly this knowledge was lost. Currently there are several competing hypotheses regarding the loss of the formula for Damascus steel. One hypothesis is that the loss of knowledge had to do with the community's secrecy that led to its eventual demise. In general, ancient metallurgical practices were not inscribed in writing. Most of our current knowledge on ancient metallurgical practices comes from studying excavated forges and workshops alongside a scarce body of surviving manuscripts (Long \& Roland, 1994, pp. 266-267). Furthermore, given the technical nature of the work and the great value placed on good steel, the knowledge would be passed down from smiths almost exclusively to their apprentices (Verhoeven, Pendray, \& Dauksch, 1998). While there are surviving manuscripts that attempt to describe the Damascus steel production process, any attempts to use these descriptions to recreate the process have proved lacking. Thus, it is likely that these descriptions were intentionally made difficult to follow in efforts to thwart non-community members' understanding (Khorasani \& Hynninen, 2013, pp. 166-167). But even if there was a way of decoding these recipes, the end of Damascus steel production in the eighteenth to nineteenth centuries (Verhoeven, Pendray, \& Dauksch, 1998) indicates that even this knowledge was no longer transmitted. While this may turn out to be an instance of theory decay, it seems more likely that the community of smiths simply ceased to exist as a result of the specific sociopolitical and environmental situation of the time. Specifically, because of heavy taxation, land settlement policies, and droughts, it became increasingly difficult for the community of smiths to maintain their members (Lewis, N. 1955, pp. 48-50, 57-58). Thus, if this hypothesis is correct, we are likely dealing not with theory decay, but with agent discontinuity where the respective production knowledge died off with the select few who knew it. 
Another hypothesis concerning the loss of Damascus steel is that the ingots necessary to bring out the unique features of Damascus steel were no longer sourced. When analyzing the chemical composition of Damascus steel, many have found that the blades contain high trace amounts of chromium, molybdenum, niobium, manganese, and vanadium, as well as high levels of phosphorous, which help create the microstructure of Damascus steel (Verhoeven et al., 2018). Some have speculated that this composition was localized to the wootz ingots sourced in Southern India (Verhoeven, Pendray, \& Dauksch, 1998; Panseri, 1965, pp. 25-26; Horning, n.d.). Recreations by Hynninen show the importance of the ingots' composition, as attempts with steel with different compositions resulted in minimal surface patterns (Khorasani \& Hynninen, 2013, pp. 159,167, 169). If this hypothesis regarding the change in ingot sourcing is true, the absence of chemical impurities meant that it was impossible to create Damascus steel, even when the same techniques and recipes were used. If so, Damascus steel would be a case of theory decay, as the knowledge of its production was not rejected, but lost when it was no longer possible to recreate.

At the moment, both of these hypotheses seem equally plausible, and more research is needed to establish that this was in fact a case of theory decay rather than mere agent discontinuity. If the community of smiths itself disappeared due to sociopolitical and environmental circumstances, then we would not have a case of theory decay. If, on the other hand, it turns out that the community continued to exist, but the knowledge wasn't transmitted to the next generations due to the lack of necessary material to create the blades, then we would have a solid indication of theory decay. Until there is sufficient historical evidence to favour one historical account over the other, it is inconclusive whether the knowledge for creating Damascus steel was lost due to theory decay.

\section{Case 4: Greek Fire}

Another famous case of lost knowledge is that of Greek fire, an incendiary weapons system used by the Byzantine empire from 678-1204 CE, most notably during the first and second Arab sieges of Constantinople in 674-678 and in 717-718 (Long \& Roland, 1994, p. 276). According to the 8-9 $9^{\text {th }}$ century Byzantine chronicler Theophanes the Confessor, Greek fire was invented during the first Muslim siege of Constantinople by an artificer from Heliopolis of Syria by the name of Kallinikos. Greek fire was characterized by its liquid form and ability to burn in water; when used in navel combat, it volleyed like artillery towards the enemy with cacophonous thunder. While other incendiary weapons existed during this time (Roland 1992, pp. 655-658; Partington 1999, pp. 10-12, 15), none was as effective as Greek fire. Despite all the efforts to preserve its formula, the knowledge of Greek fire had been completely lost by the time of the Sack of Constantinople by the Fourth Crusade in 1204. This makes it a potentially promising search direction for theory decay.

Given the firepower advantage of Greek fire, there was a clear incentive to keep its formula a secret. Such secrecy surrounding Greek fire contrasts with the extensive Byzantine tradition of producing texts on weapon production, as well as military strategy and tactics. Such conventional military knowledge was openly accessible and read by military leaders and generals in training. In contrast, to prevent the proliferation of its formula, Greek fire was produced and bottled on-site, with its production process compartmentalized. Its use was even limited in combat, as exposing the enemy to the weapons system increased the possibility of copycat weapons systems or defensive measures. If this attempt at secrecy wasn't explicit enough, Emperor Constantine VII Porphyrogenitus (913-959 CE) advised his son that the knowledge of Greek fire should be restricted only to Byzantine rulers. Thus, to maintain the secret, the transmission of knowledge was kept limited to a select number of people who passed this knowledge down to their next generations to safeguard it not only from other nations but also from their potential enemies within Byzantium. As a result, even when Byzantine ships were captured and Greek fire came into enemy hands, it was unlikely that it could be successfully replicated. For instance, in 814, Bulgars captured 36 siphons of Greek fire but apparently didn't know how to use it (Long \& Roland, 1994, pp. 275-277, 279; Roland, 1992, pp. 662-665, 671-673). 
It is safe to say that by the year 1204 the knowledge of Greek fire had already been lost, as there is no record of its use during the Sack of Constantinople or afterwards (Long \& Roland, 1994, p. 277). There is good evidence that the formula was lost long before 1204, as later accounts of Greek fire became increasingly contentious (Roland 1992, p. 666). We can assume that the Emperor Constantine VII knew the formula; otherwise, his advice to keep it a secret would make no sense. Thus, we can conclude that the formula was lost sometime after his death in 959. Writings by Anna Komnene (1083-1153 CE), a Byzantine princess and scholar, indicate that her father, Emperor Alexius I (1057-1118 CE) knew the formula as he personally supervised the construction of special ships for the use of Greek fire. While Anna Komnene provided a recipe for Greek fire in her writings, it was notably incomplete (Roland 1992, pp. 665-666), casting doubt on whether Emperor Alexius I actually knew the original formula. It is likely, therefore, that the original formula of Greek fire was lost sometime between the death of Emperor Constantine VII and the death of Anna Komnene, i.e. sometime between 959 and 1153.

This gives us a period of almost 200 years, which makes it difficult to know how exactly this knowledge was lost. There are two scientonomically relevant scenarios here. It is conceivable that the community in question continued to exist but, at some point, failed to pass the original formula down to the next generation;

According to the $11^{\text {th }}$ century Byzantine chronicler George Kedrenos, some version of the formula of Greek fire was still possessed by the family of "Lampros", descendants of Kallinikos, who continued to manufacture Greek fire in his own time. However, Kedrenos did not specify whether this was the original formula that was known to Emperor Constantine VII (Partington 1999, pp. 20-21). In any event, this story lacks any independent corroboration; nowadays, it is considered highly unlikely that "the secret of the fuel had remained confined to the members of one private and obscure family and had been handed down within it from generation to generation for six centuries" (Prior \& Jeffreys, 2006, p. 608).

that would be a case of theory decay. However, it seems

much more likely that the loss of knowledge in this case was due to agent discontinuity. First, in the period between 674 and 1153, Byzantium was ruled by members of seven different dynasties (Heraclian, Isaurian, Nikephorian, Amorian, Macedonian, Doukid, and Komnenid). On several occasions, long dynastic periods were followed by non-dynastic rulers as well as periods of anarchy. Unsurprisingly, dynastic rules often ended as a result of regicide bringing the emperor's line to a bloody end. These considerations make any claims of the existence of one continuous communal agent extremely problematic. Even if we consider the period between 959 and 1153, we are dealing with three different dynasties and an endless number of revolts. Given the violent nature of these successions and that the knowledge of the formula for Greek fire was likely restricted to Byzantine rulers, it is hard to imagine that rulers who were unwilling to concede their rule would be nevertheless willing to share the formula for Greek fire. Speaking of one continuous agent in such circumstances is not an option.

In short, it is quite likely that the loss of knowledge of Greek fire was due to agent discontinuity rather than theory decay. The current historical evidence seems to suggest that we are dealing not with one continuous agent but with several competing communal agents that lacked any incentive to pass the knowledge to each other. As interesting as this historical case is, it appears that the loss of formula for Greek fire is not an instance of theory decay.

\section{Case 5: Cremonese Violins}

Our final case is that of the loss of technical knowledge required for the construction of quality Cremonese violins. The Italian village of Cremona is the home of a long lineage of violin making practices that span centuries. Known now as a Mecca for prospective luthiers, it was the home of some of the great violin luthiers of the golden age of violin making, such as Nicola Amati (1596-1684), Antonio Stradivari (1644-1737), Bartolomeo Giuseppe Guarneri del Gesu (1698-1744), and Carlo Bergonzi (1683-1747) (Rosengard, 1992, p. 91; Gindin \& Rosengard, 2002, p. 23; Hsieh, 2004, p. 29). While the legacy of these masters is enough of a lure for tourists, many still visit in efforts to acquire a Cremonese violin. Violins here are renowned for their unique "Italian sound", described as "warm" and "full of harmonics" (Jarosy \& Fiedler, 1935; Wali, 2010, p. 114; Rotaru, n.d.). In more quantifiable terms, Cremonese violins have unique acoustical qualities, as they can produce a broader frequency range. The golden age of Cremonese violins came to an end after the deaths of Stradivari in 1737, Guarneri in 1744, and 
Bergonzi in 1747 (Rosengard, 1992, p. 91; Hsieh, 2004, p. 29) and was followed by what is known as post-golden or late Cremonese period which lasted till the early $20^{\text {th }}$ century (Gindin \& Rosengard, 2002). The instruments produced in this late Cremonese period were more simplified and less punctilious in their manner of execution. They were far less beautiful and composed of far cheaper wood, failing to meet the earlier standards of elegance and finesse that Cremonese violins were renowned for (Jarosy \& Fiedler, 1935). Another notable difference is that of varnish (Cattani, Dunbar, \& Shapira, 2013). This era saw the use of alcohol-based varnishes that dried much quicker (Dilworth, 2001), leading to a great variety of color and texture. In contrast, oil-based varnishes used before 1744 had a clear resemblance with one another and differed primarily in color and in the thickness of application (Niederheitmann \& Quarrell, 1894, p. 14). There is currently no consensus among the experts as to what the Cremonese violins owe their unique sound; it is safe to say that the wood receives more credit than the varnish (Cattani, Dunbar, \& Shapira, 2013, p. 823).

Since apprentices tried as much as possible to follow in the styles of their masters - almost to the point of imitation - these differences cannot be excused as mere stylistic changes. Clearly, sometime during this postgolden period, some of the technical knowledge possessed by the masters of the golden age was lost, which makes it reasonable to inquire whether this was an instance of theory decay.

To determine whether we are indeed facing an instance of theory decay here, we must first ascertain that there was a continuous community for the whole duration of the period in question. Given the highly technical nature of violin craftsmanship, this knowledge has historically been transmitted through tight master-apprentice relationships. Techniques in violin making were not transmitted in writing but through physical practice and oral teachings. Historically, apprentices would live in their master's estates, having a perfect environment to learn the tools of the trade. As apprentices learned the craft, they would learn how to produce each piece, even helping their masters, before making their own violins. Additionally, violin making was hereditary - just as some parents nowadays train their children to inherit the family trade, so too did fathers of this era enlist their children as apprentices (Gindin \& Rosengard, 2002, p. 26). When a master passed away, the children usually inherited the workshop, the violin tools (like the violin molds), the master's name-recognition, and the knowledge that was taught to them by the master. Secrecy was another factor to the master-apprentice mode of transmission. Given the competition not only within the community, but with all violin makers, masters shared their knowledge only with their apprentices. Apprentices also had an incentive to carry this secrecy, as the name-recognition of their masters meant a consistent supply of work (Cattani, Dunbar, \& Shapira, 2013). All of this meant that the knowledge was highly localized to the Cremona area and was not widely disseminated. Therefore, if we manage to show that there was a clear continuity from a master to apprentice starting in the golden age and continuing well into the post-golden period, then we will be able to claim that this was an instance of theory decay.

While some historical accounts of Cremonese violin history depict the death of Carlo Bergonzi in 1747 as the end of Cremonese violin making (Rosengard, 1992, p. 91; Mosconi, 2001, p. 22), Cremonese violin making continued beyond that date, although the quality of its output declined due to political and economic changes. In this late Cremonese period, the demand for violins shifted from highly nuanced instruments played in royal courts to cheaper and more accessible items for the mass public; the special qualities exhibited by the Cremonese violins of the golden age were of little interest to this market (Gindin \& Rosengard, 2002, pp. 23, 43). Furthermore, the death of Stradivari in 1737 meant that Cremona had lost the unique name-brand that Stradivari had brought to his instruments. As a result of declining sales, the profession of a luthier became less popular and Cremona lost their status as a prestigious location for violin production (Wali, 2010, pp. 22, 113). It wasn't until the nineteenth century when many notable violinists started using Stradivarius violins for public performances, gradually bringing about a renewed demand for a Stradivarius, and by extension, for other Cremonese violins (Cattani, Dunbar, \& Shapira, 2013). Following this demand, the Cremona International Violin Making School was established in September 1938 in order to maintain and recreate Cremonese violin making practices.

Given the gap of nearly 200 years, one may have reservations that we can legitimately speak of the same continuous community of luthiers. After all, it might be tempting to interpret the death of the great masters as the end of the community itself. However, there is solid historical evidence indicating that the community of 
originally Cremonese luthiers continuously existed well into the post-golden period. Because official apprentices resided in their master's estates as part of their training, censuses, workshop registration, and genealogical documents allow us to trace the continuity of the community. Additionally, this continuity is confirmed by city records that indicated the respective professions of people.

As the Cremonese style is best exemplified in the violins of Stradivari, it seems reasonable to begin our reconstruction of the lineage with Stradivari. After working as an employee of Nicola Amati, Stradivari would go on to open his own workshop in Cremona ca. 1680 and produce some of the most sought-after violins with auction prices "reaching into the millions of dollars" (Catani, Dunbar, \& Shapira, 2013, pp. 813, 817). One of Antonio Stradivari's apprentices was Carlo Bergonzi. The connection between the Stardivari and the Bergonzi family was so established that when Stradivari's son Paolo died in 1746, Bergonzi's family moved into Stradivari's workshop. Carlo, though not as renowned for his work as his contemporary del Gesu, had produced multiple violins in the Cremonese style. By the time Carlo passed away in 1747, he had already begun to train his sons Michele (17211758) and Zosimo (1724-1779) as apprentices. Both were trained enough to have similar workmanship as their father, but their lack of experience resulted in violins that were less aesthetically refined. After Carlo's death, Michele inherited the Stradivari workshop and continued to work as a luthier until his death in 1758 (Rosengard, 1992, pp. 92-94, 112). Violins produced by Michele still had the appearance and tonal capacities that defined Cremonese violins; yet he did not use the varnish formula of his predecessors from the golden age (Gindin \& Rosengard, 2002, pp. 24-25, 44). After his death, the workshop itself was inherited by his brother Zosimo. While Zosimo did not lead the workshop as a master, he had created violins on multiple occasions. The nature of Zosimo's primary occupation remains a mystery; what is important here is that, given his training, he would have possessed the sufficient knowledge to teach his sons Nicola (1754-1832) and Carlo II (1757-1836) how to create violins, though one may doubt whether he did so (Gindin \& Rosengard, 2002, pp. 26, 64; Rosengard, 1992, p. 95). Regardless of whether Zosimo had taught his sons, they had nonetheless learned to make violins in the Cremonese style. While Nicola's instruments were somewhat rough and crude, they were still modeled after the Stradivari design and held a "Bergonzi character". For example, the sound holes of his violins are positioned closer to the edge with wings that swing outwards towards the bottom, which is a characteristic shared by del Gesu, Carlo, and Michele. The same goes for Carlo II, as the likeness between their work had resulted in a misidentification of Carlo II's work as a Nicola. Nicola had begun to run his own workshop, registering it in 1787 in compliance with the changes made by the Mercantile Chamber of Cremona. Nicola would abandon violin making sometime in the 1790s, making his last known violin in 1796 (Rosengard, 1992, pp. 97, 99, 101, 122, 126; Gindin \& Rosengard, 2002, pp. 71, 73). Carlo II, after a brief period as a cloth dealer, became a registered official musical instrument maker in 1812 (Rosengard, 1992, p. 101). However, the scarcity of his violins indicate that he did not create violins consistently. Yet, Carlo II's reputation and knowledge of the Cremonese style is confirmed by the fact that Luigi Tarisio, an Italian violin dealer and collector famous for his acquisition of Stradivari violins, consulted Carlo II to confirm the style of some of the Amati and Stradivari violins that he had acquired (Gindin \& Rosengard, 2002, p. 98). Thus, we can safely conclude that there was a certain continuity of the communal epistemic agent from the golden age well into the post-golden period, as can be seen in the following influence diagram: 


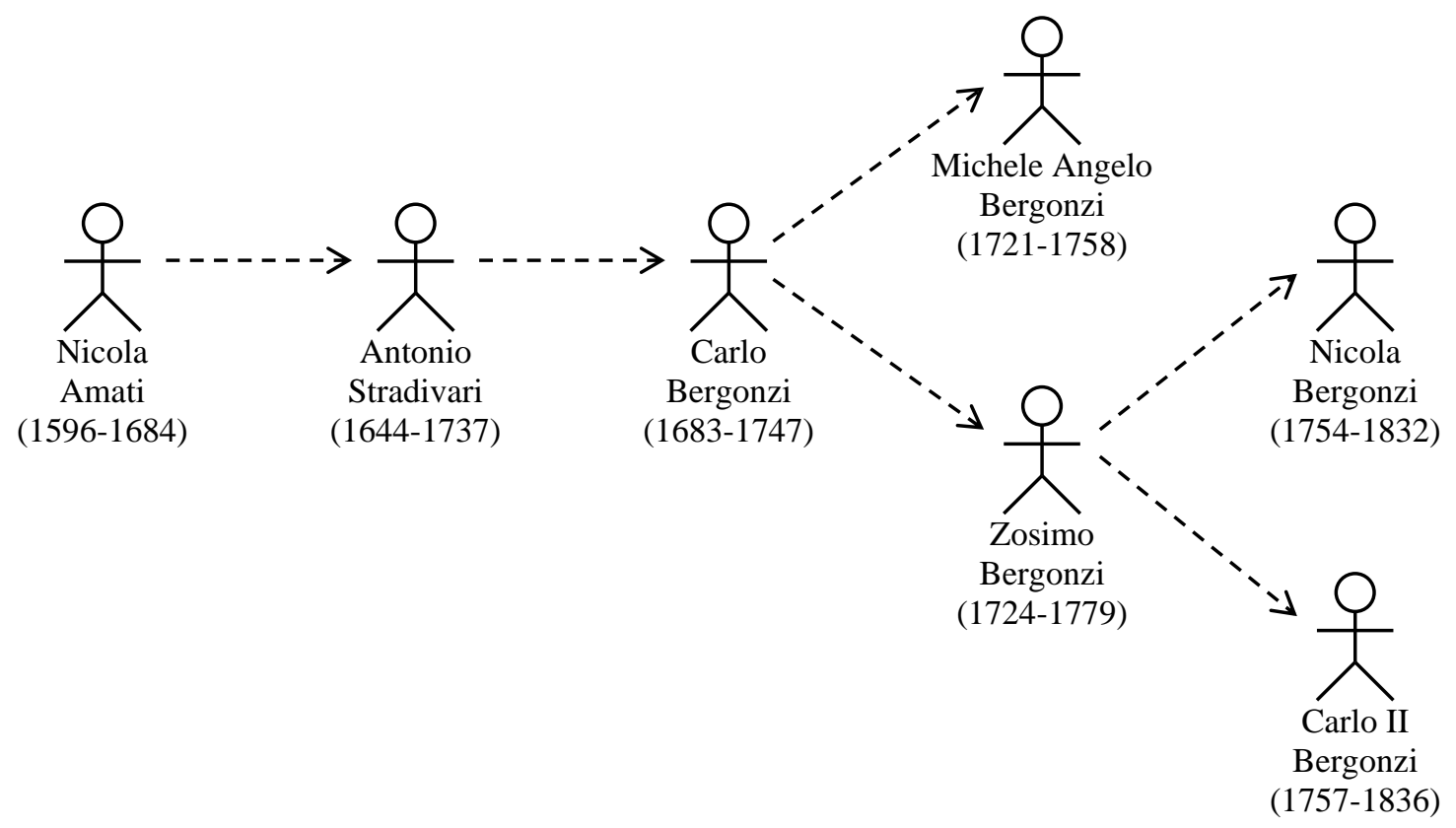

This lineage of masters and apprentices can be traced all the way to the establishment of the Cremona International Violin Making School in 1938. An important figure in this lineage is Lorenzo Storioni (1745-1816), who did not have the classic apprenticeship that has defined the transmission of knowledge up to this point but who was clearly part of the same community, as evidenced by the fact that his violins reflected the Cremonese style. Many scholars have asserted that his knowledge comes from his proximity to the estate of the Bergonzis. From 1787 to 1789 , Nicola Bergonzi and Storioni had workshops around the corner from one another, even becoming co-inhabitants between 1790-1795 (Rosengard, 1992, pp. 104-107, 130). When Storioni left Cremona in 1802, his work was continued by Giovanni Battista Ceruti, who produced a significant number of instruments (1756-1817). While there is a debate as to whether Giovanni was an apprentice of Storioni, there was a clear personal connection between the two, indicated, among other things, by the clearly recognizable Bergonzi style of his work (Gindin \& Rosengard, 2002, pp. 26, 71, 121, 120). Giovanni would personally teach his grandson, Enrico Ceruti (18061883), a professional double bassist, who would also go on to produce a plethora of violins (Gindin, \& Rosengard, 2002 , pp. 26-27, 197-201). He was documented as a "maker of instruments" in the early 1830s and a "restorer of instruments" in 1848. Enrico had collected old forms, drawings, and tools, even going at lengths to revive the past styles. For instance, the neck of his instrument was mounted directly onto the ribs in line with the traditional methods, rather than inserted into the upper part of the table. Enrico would go on to teach Gaetano Antoniazzi (1825-1897), who moved to Milan in 1870. Gaetano's works, albeit of mixed quality, still exhibited the traditional style with careful edges that were slightly raised and well rounded, flat and broad or slightly pinched archings and characteristic channeling (Gindin \& Rosengard, 2002, pp. 27, 248-254, 280-283). Gaetano himself would train many Italian violin makers in Milan, including his sons Riccardo (1853-1912) and Romeo (1862-1925), along with Leandro Bisiach (1864-1945), who first studied with Riccardo in 1886 and then established his business in Milan ca. 1890. Over the years, Bisiach employed many notable luthiers including Ricardo's father Gaetano and brother Romeo. He greatly contributed to the diffusion of the Cremonese style in Milan, turning the city into a major center for violin production. As for luthiers in Cremona, after Gaetano Antoniazzi's exodus to Milan in 1870, there were still some notable violin makers like Giuseppe Beltrami (1830-1881). However, their work was typically far cruder in workmanship, to the point where the unique Cremonese style was virtually unrecognizable. Thus, the Cremonese style was mostly preserved in Milan and returned to Cremona with the founding of the Cremona International Violin Making School in 1938, whose mission was to maintain and rediscover the art of the Cremonese violin-making process back to the caliber of Stradivari (Gindin \& Rosengard, 2002, p. 28). In short, there is a clear lineage of masters and apprentices that goes back into the golden age and continues 
throughout the whole period of the purported theory decay. The second half of the lineage is shown in the following influence diagram:

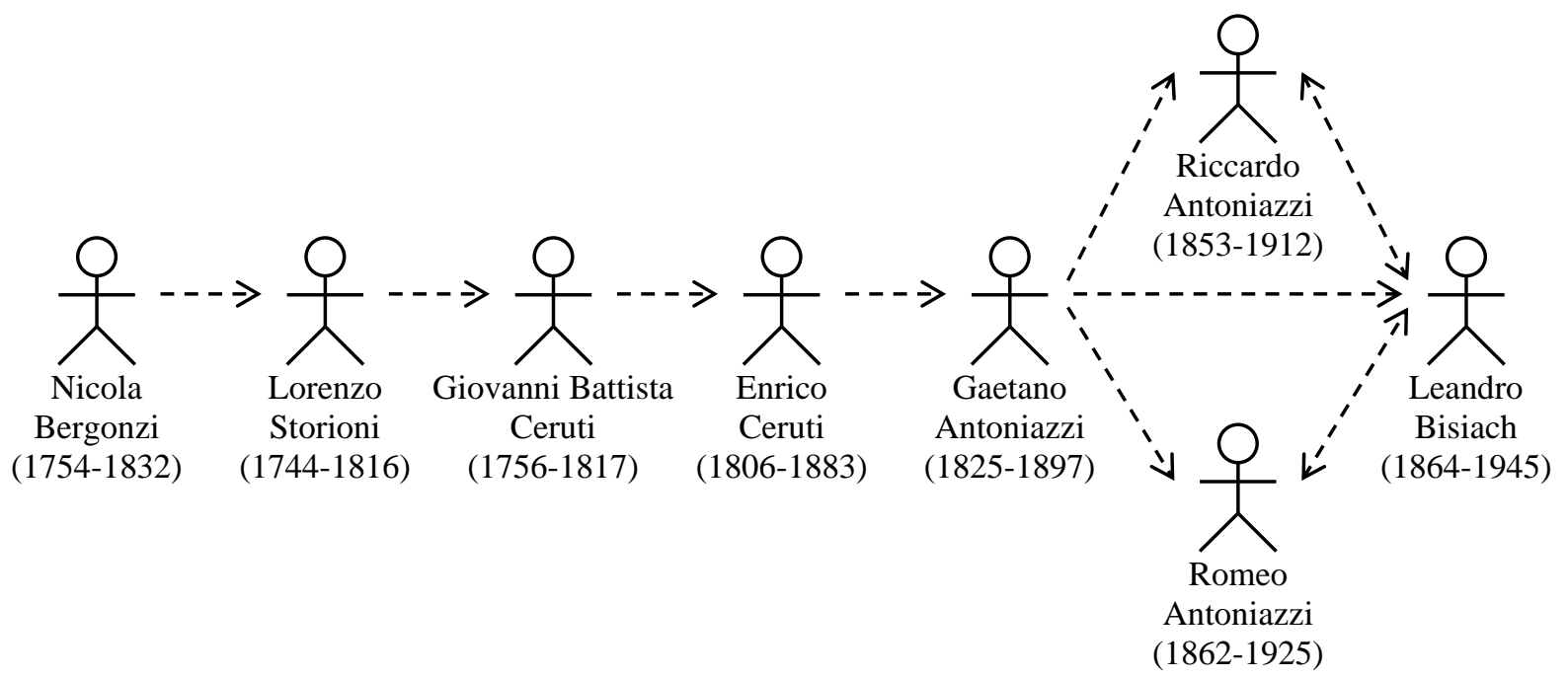

Thus, we cautiously suggest that there was a continuous community for the whole duration of the period as indicated by the uninterrupted master-apprentice lineage. This allowed the community to preserve many elements of the Cremonese style in the violins produced in the post-golden era. Yet, in some key aspects, the violins of this period were no match to those crafted in the times of Stradivari, suggesting that some of the technical knowledge was lost and, thus, indicating that we have an instance of theory decay. Importantly, this decay of technical knowledge was not a result of any deliberate decision made by Cremonese luthiers, but was most likely due to sociopolitical and economic reasons. There is solid evidence suggesting that Cremonese masters understood the importance of maintaining the distinctive Cremonese style and transferring their technical knowledge to their apprentices. However, such a transfer wasn't always smooth and was impeded by changing socioeconomic conditions. Since the transfer of this technical knowledge was facilitated by master-apprentice relationships, it was instrumental for the apprentices to be actually engaged in crafting high-quality violins to be able learn the intricate tricks of the trade. As the demand for such high-quality violins gradually declined, some of this important tacit knowledge was no longer learned by the apprentices and was therefore lost with the death of the master. In short, it appears as though we have a case of theory decay.

\section{Scientonomic Implications of Theory Decay}

Now that we have established the likely existence of theory decay (and by extension, element decay) what does this imply for our current scientonomic theory? The answer to this question, I believe, depends on our answer to the more basic question of whether the phenomenon of element decay falls within the domain of scientonomy to begin with. There are two basic options available to us at this stage: to consider element decay a scientonomic or non-scientonomic phenomenon.

If we were to choose the first option and decided to consider element decay a scientonomic phenomenon, then we would have to respond to an obvious challenge of reformulating the first law, which instances of element decay clearly violate. Indeed, if element decay were a scientonomic phenomenon, its existence would indicate that it is possible for elements of the mosaic to be rejected without any replacement; that would be a violation of the first law. This could revolutionize our understanding of the mechanism of scientific change; whichever way we altered the first law, it surely wouldn't be as straightforward as it currently is. Potentially, we might even have to consider rejecting the idea of scientific inertia altogether. That step would require us to reconsider the whole mechanism of theory rejection, which depends crucially on the notion of scientific inertia. In short, if we were to 
consider element decay a scientonomic phenomenon, that would necessitate a considerable overhaul of the current scientonomic theory.

There is, however, a more sensible second option: to leave the phenomenon of element decay outside the domain of scientonomy. Social scientists know that "individual and collective memories, inevitably, are subject

The phenomenon of knowledge loss is studied by many different fields of social science. Knowledge loss is also studied by sociologists, psychologists, and philosophers working on collective memory. As a shared body of knowledge that transcends individuals (Wertsch \& Roediger, 2008; Seemann, 2019), collective memory nevertheless shares many of the same properties with individual memory, making it prone to selective retention and, therefore, forgetting (Cicourel, 2014, p. 316; Fagin, Yamashiro, \& Hirst, 2013; Hirst, Yamashiro, \& Coman, 2018). There is also vast knowledge management literature on workable "retention strategies to reduce knowledge loss in organizations" (Daghfous, Belkhodja, \& Angell, 2013, p. 640). to limited capacity processing constraints inherent in all memory systems" (Cicourel, 2014, p. 316). Element decay is best understood as an effect of limitations in our communal and individual knowledge retention and transmission capacities. Its existence indicates that at times epistemic agents reach the limits of their capacity to retain and/or transmit knowledge without any loss. Consequently, the existence of element decay reaffirms that the laws of scientonomy are local in the sense that the patterns of scientific change only emerge and hold in very special sociocultural conditions (Barseghyan, 2015, p. 88). In this sense, scientonomic patterns are similar to other higher-level regularities that necessarily depend on the existence of some specific lower-level conditions. Thus, all social regularities have as their precondition a very specific physical, chemical, and biological environment. Likewise, biological regularities presuppose certain physicochemical conditions where life can exist and evolve (Barseghyan, 2015, p. 88). Similarly, the very existence of the patterns of scientific change presupposes sufficient epistemic capacity for knowledge retention and transmission. Among many other things, this requires certain strategies to counteract the inherent limitations of individual memories and communal capacities for knowledge retention and transmission. It is agreed upon in the literature that "the likelihood of knowledge loss increases as individuals become the repositories for knowledge" (Cattani, Dunbar, \& Shapira, 2013, p. 824). In contrast, communal knowledge is generally "more resistant to deprecation and more easily transferred" (Argote, 1999, p. 93). But even when there are communal repositories of knowledge in place, it can still be lost if it is tacit, i.e. if it is not explicitly stated (MacKenzie \& Spinardi, 1995, p. 46). For example, as the knowledge of Cremonese luthiers was largely tacit and its transmission relied heavily on "face-to-face mentoring, demonstration, and coaching", it is unsurprising that some of this tacit knowledge was eventually lost (Cattani, Dunbar, \& Shapira, 2013, pp. 821, 822; for a discussion of tacit knowledge, see Barseghyan \& Mirkin, 2019). The existence of sufficient epistemic capacity of knowledge retention and transmission is, therefore, a necessary prerequisite for the changes in the agent's mosaic to exhibit scientonomic patterns. Only when the agent has mechanisms to counteract potential element decay can the patterns of scientific change emerge and hold. In short, there are solid reasons to believe that element decay exists, but it is purely non-scientonomic in nature and falls outside the scope of scientonomy.

\section{Acknowledgements}

I would like to thank Kye Palider, Nichole Levesley, Hakob Barseghyan, and the anonymous reviewer for their insightful comments and suggestions.

\section{Suggested Modification}

I suggest the following modification:

\section{[Sciento-2021-0005]}

Accept that there is element decay, a phenomenon where elements of an agent's mosaic cease to be part of the mosaic without any re-evaluation by the agent or any decision to reject that element.

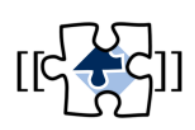


Accept the following as necessary indicators of theory decay:

- Agent Continuity: there should be historical evidence that the agent in question continuously existed during the time period under study.

- Change from Theory Acceptance to Unacceptance: there should be clear indications of a theory being accepted at some point and unaccepted at some later point.

- Theory Unacceptance Without Assessment: there should be clear evidence that the theory became unaccepted without any theoretical assessment on the part of the agent.

Also accept that element decay is a non-scientonomic phenomenon.

\section{References}

Argote, L. (1999). Organizational Learning. Creating, Retaining, and Transferring Knowledge. Kluwer Academic Publishers.

Aunger, R. (2000). The Life History of Culture Learning in a Face-to-Face Society. Ethos 28(2), pp. 1-38.

Barseghyan, H. (2015). The Laws of Scientific Change. Springer.

Barseghyan, H. \& Mirkin, M. (2019). The Role of Technological Knowledge in Scientific Change. In Héder \& Nádasi (Eds.) (2019), pp. 5-17.

Bellhouse, D. R. (2011). Abraham De Moivre: Setting the Stage for Classical Probability and its Applications. CRC Press.

Bellhouse, D. R. \& Genest, C. (2007). Maty's Biography of Abraham De Moivre, Translated, Annotated and Augmented. Statistical Science 22(1), pp. 109-136.

Berry, M. (2010). Aptly Named Aharonov-Bohm Effect Has Classical Analogue, Long History. Physics Today 63(8), pp. 89.

Bird, A. (2018). Thomas Kuhn. In Zalta, E. N. (Ed.) (2017). The Stanford Encyclopedia of Philosophy (Winter 2018

Edition). Retrieved from https://plato.stanford.edu/archives/win2018/entries/thomas-kuhn/.

Cattani, G.; Dunbar, R. L. M.; \& Shapira, Z. (2013). Value Creation and Knowledge Loss: The Case of Cremonese Stringed Instruments. Organization Science 24(3), pp. 813-830.

Cicourel, A. V. (2014). Collective Memory, a Fusion of Cognitive Mechanisms and Cultural Processes. Revue De Synthèse 136(6), pp. 309-328.

Crosland, M. (2005). Relationships Between the Royal Society and the Acadmie des Sciences in the Late Eighteenth Century. Notes and Records of the Royal Society of London 59(1), pp. 25-34.

Daghfous, A.; Belkhodja, O.; \& Angell, L. C. (2013). Understanding and Managing Knowledge Loss. Journal of Knowledge Management 17(5), pp. 639-660.

Dilworth, J. (2001). Varnish. Grove Music Online. Retrieved from https://www.oxfordmusiconline.com/grovemusic/view/10.1093/gmo/9781561592630.001.0001/omo-9781561592630-e0000041471.

Fagin, M.; Yamashiro, J.; \& Hirst, W. (2013). The Adaptive Function of Distributed Remembering: Contributions to the Formation of Collective memory. Review of Philosophy and Psychology 4(1), pp. 91-106.

Fatigati, M. (2017). A Method for Reconstructing the Medieval Arabic Scientific Mosaic. Scientonomy 1, pp. 19-28.

Retrieved from https://www.scientojournal.com/index.php/scientonomy/article/view/27761.

Gindin, D. \& Rosengard, D. (2002). The Late Cremonese Violin Makers. Novecento.

Gómez-Baggethun, E.; Mingorria, S.; Reyes-García, V.; Calvet, L.; \& Montes, C. (2010). Traditional Ecological Knowledge Trends in the Transition to a Market Economy: Empirical Study in the Donana Natural Areas. Conservation Biology 24(3), pp. 721-729.

Gough, C. E. (2016). Violin Acoustics. The Acoustics of Thin-Walled Shallow Boxes - a Tale of Coupled Oscillators. Acoustics Today 12(2), pp. 22-30.

Godfrey-Smith, P. (2003). Theory and Reality: An Introduction to the Philosophy of Science. University of Chicago Press. Greenberger, D.; Hentschel, K.; \& Weinert, F. (Eds.) (2009). Compendium of Quantum Physics. Springer.

Hald, A.; de Moivre, A.; \& McClintock, B. (1984). A. de Moivre: 'De Mensura Sortis' or 'On the Measurement of Chance'. International Statistical Review 52(3), pp. 229-262. 
Héder, M. \& Nádasi, E. (Eds.) (2019). Essays in Post-Critical Philosophy of Technology. Vernon Press.

Heyde, C. C. \& Seneta, E. (2001). Statisticians of the Centuries. Springer.

Hiley, B. J. (2013). The Early History of the Aharonov-Bohm Effect. arXiv. Retrieved from https://arxiv.org/abs/1304.4736.

Hirst, W. K.; Yamashiro, J. K.; \& Coman, A. K. (2018). Collective Memory from a Psychological Perspective. Trends in Cognitive Sciences 22(8), pp. 438-451.

Horning, J. (n.d.). Damascus Steel. Retrieved from https://engineering.purdue.edu/MSE/aboutus/gotmaterials/History/horning.html.

Hoyningen-Huene, P. (2008). Thomas Kuhn and the Chemical Revolution. Foundations of Chemistry 10(2), pp. 101-115. Hsieh, A. (2004). Cremona Revisited: The Science of Violin Making. Engineering and Science 67(4), pp. 28-35.

Jarosy, A. \& Fiedler, H. (1935). The Secret of the Italian Violin Makers. Music \& Letters 16(2), pp. 116-123.

Johnson, N. L.; Kemp, A. W.; \& Kotz, S. (1992). Univariate Discrete Distributions. Wiley.

Khorasani, M. M. \& Hynninen, N. (2013). Reproducing Crucible Steel: A Practical Guide and a Comparative Analysis to Persian manuscripts. Gladius 33, pp. 157-192.

Kuhn, T. (1973). Objectivity, Value Judgement, and Theory Choice. In Kuhn (1977), pp. 320-339.

Kuhn, T. (1977). The Essential Tension. The University of Chicago Press.

Kuhn, T. (1996). The Structure of Scientific Revolutions. Third Edition. The University of Chicago Press.

Lakatos, I. (1970). Falsification and the Methodology of Scientific Research Programmes. In Lakatos (1978), pp. 8-101.

Lakatos, I. (1978). Philosophical Papers: Volume 1. The Methodology of Scientific Research Programmes. Cambridge University Press.

Laudan, L. (1977). Progress and its Problems. University of California Press.

Lewis, N. (1955). The Frontier of Settlement in Syria, 1800-1950. International Affairs 31(1), pp. 48-60.

Long, P. O. \& Roland, A. (1994). Military Secrecy in Antiquity and Early Medieval Europe: A Critical Reassessment. History and Technology 11(2), pp. 259-290.

Lyre, H. (2009). Aharonov-Bohm Effect. In Greenberger, Hentschel, Weinert (Eds.) (2009), pp. 1-3.

MacKenzie, D. \& Spinardi, G. (1995). Tacit Knowledge, Weapons Design, and the Uninvention of Nuclear Weapons. American Journal of Sociology 101(1), pp. 44-99.

Mosconi, A. (2001). Cremona's Instruments: The Town Hall and the Collection of Stringed Instruments. Cremonabooks.

Niederheitmann, F. \& Quarrell, W. H. (1894). Cremona: An Account of the Italian Violin-Makers and Their Instruments. Robert Cocks \& Co.

Panseri, C. (1965). Damascus Steel in Legend and in Reality. Gladius 4, pp. 5-66.

Partington, J. R. (1999). A History of Greek Fire and Gunpowder. The Johns Hopkins University Press.

Peshkin, M. \& Tonomura, A. (1989). The Aharonov-Bohm Effect. Springer.

Poisson, S.-D. (2013). Researches into the Probabilities of Judgements in Criminal and Civil Cases. Translated by Oscar Sheynin. arXiv. Retrieved from https://arxiv.org/ftp/arxiv/papers/1902/1902.02782.pdf

Preece, D.; Ross, G.; \& Kirby, P. (1988). Bortkewitsch's Horse-Kicks and the Generalised Linear Model. Journal of the Royal Statistical Society. Series D (The Statistician) 37(3), pp. 313-318.

Prior, J. H. \& Jeffreys, E. M. (2006). The Age of the $\triangle P O M \Omega N$. The Byzantine Navy ca 500-1204. Brill.

Reyes-García, V.; Broesch, J.; Calvet-Mir, L.; Fuentes-Pelaez, N.; McDade, T. W.; Parsa, S.; Tanner, S.; Huanca, T.; Leonard, W. R.; Martínez-Rodríguez, M. R.; \& TAPS Bolivian Study Team, Tsimane' Amazonian Panel Study (TAPS), Correo Central. (2009). Cultural Transmission of Ethnobotanical Knowledge and Skills: An Empirical Analysis from an Amerindian Society. Evolution and Human Behavior 30(4), pp. 274-285.

Roland, A. (1992). Secrecy, Technology, and War: Greek Fire and the Defense of Byzantium, 678-1204. Technology and Culture 33(4), pp. 655-679.

Rosengard, D. (1992). Cremona after Stradivari: The Bergonzi and Storioni Families. Journal of the Violin Society of America 12(1), pp. 91-162.

Rotaru, F. D. (n.d.). Italian Sound. Retrieved from http://felixrotaru.com/italian-sound/.

Seemann, A. (2016). Reminiscing Together: Joint Experiences, Epistemic Groups, and Sense of Self. Synthese 196(12), pp. 4813-4828.

Sherby, O. D. \& Wadsworth, J. (2001). Ancient Blacksmiths, the Iron Age, Damascus Steels, and Modern Metallurgy. Journal of Materials Processing Technology 117(3), pp. 347-353.

Sheynin, O. B. (2017). Theory of Probability. A Historical Essay. arXiv. Retrieved from https://arxiv.org/abs/1802.09966.

Sturrock, P. A. \& Groves, T. R. (2010). More Variations on Aharonov-Bohm. Physics Today 62(9), p. 38. 
The Royal Society (2007). List of Fellows of the Royal Society 1660-2007. Retrieved from

https://web.archive.org/web/20071212012209/http://royalsociety.org/downloaddoc .asp?id=4275.

Verhoeven, J. D.; Pendray, A. H.; \& Dauksch, W. E. (1998). The Key Role of Impurities in Ancient Damascus Steel Blades. The Journal of The Minerals, Metals \& Materials Society 50(9), pp. 58-64.

Verhoeven, J. D.; Pendray, A. H.; Dauksch, W. E.; \& Wagstaff, S. R. (2018). Damascus Steel Revisited. The Journal of The Minerals, Metals \& Materials Society 70(7), pp. 1331-1336.

Wali, K. C. (2010). Cremona Violins: A Physicist's Quest for the Secrets of Stradivari. World Scientific.

Wertsch, J. V. \& Roediger, H. L. (2008). Collective Memory: Conceptual Foundations and Theoretical Approaches. Memory 16(3), pp. 318-326. 